\title{
A relação teoria e prática na formação de professores de História: a experiência de laboratórios de ensino de História (1980-2010)
}

Relation teory and practice in formation of teachers of history in brazil and portugal (1980-2010)

Marilú Favarin Marin* (In memorian) ${ }^{1}$

Universidade Federal de Santa Maria

Resumo Este estudo toma como princípio a compreensão da existência de uma "Didática da História" como aporte do aprendizado docente na formação de professores de História e das suas práticas no ensino da disciplina de História. Também toma como base a produção do teórico alemão Jörn Rüsen na busca da conceituação para a categoria Didática da História como um campo de análise dos fundamentos da Educação Histórica, a qual cumpre papel central no processo de reflexão sobre as atividades dos historiadores.

PALAVRAS-CHAVE: Didática da história; Formação de professores; Ensino de História.

Abstract This study considers the understanding of a "History Didactics" existence as a teaching learning contribution in the education of History' teachers and their practices in the History discipline teaching. It also includes, in its starting point, the production of the German theorist Jörn Rüsen in his research concept to the History Didactics category as a field of analysis to the foundations of the History Education, which has a central role in the process of reflection on historians' activities.

KEYWORDS: Didactics of history; Teachers education; Teaching of History. 
Rüsen (2006) expõe a trajetória histórica da disciplina da didática da história na Alemanha a partir das décadas de 1960-70, na transição de disciplina pragmática e externa aos estudos históricos para uma perspectiva reflexiva da sociedade e o conhecimento histórico. Foi nesse momento que naquele país começou a se desenvolver análise sobre a própria ciência da história e dela como espaço de construção da autoconsciência desse campo. $\mathrm{O}$ autor usa o caso para ilustrar a discussão sobre como é pensada a história na Alemanha e em outros países da Europa Ocidental (como Inglaterra, França, Espanha e Portugal), quais as origens da história na natureza humana, e quais seus usos para a vida humana. Para ele estas são questões básicas que uma didática da história válida deveria considerar e que poderia fazer desta disciplina parte integral e importante dos estudos históricos. Descreve, ainda, neste trabalho, o estado atual da disciplina de didática da história com seus novos objetos, temáticas principais e perspectivas futuras.

Nesse trabalho Rüsen escreve que a didática da história é tradicionalmente compreendida como uma disciplina que faz parte da formação de professores de história e que exerce o papel de mediadora entre a transposição do conhecimento acadêmico para os ensinamentos de história na escola básica. Ou seja, ela vem contribuindo, em caráter restrito, para o ensino da história na escola. Esse caráter restrito a coloca à parte do trabalho dos historiadores no estudo do seu próprio campo. Essa interpretação é definida por Rüsen (2006) como enganosa, uma vez que falha em confrontar o que se ensina na história com as necessidades da vida prática; falha na relação entre didática da história e pesquisa histórica; e, falha ainda enquanto limita as perspectivas dos historiadores quanto aos princípios da sua disciplina.

Antes de pensar a história como um campo de pesquisadores, relembra Rüsen, o debate existente focava a relação da história com o processo de ensino e aprendizagem, sendo seu objetivo, da Antiguidade ao Século XVIII, o de orientar para a moral e problemas práticos da vida. Durante o Iluminismo, os historiadores profissionais debatiam os princípios didáticos da escrita da história como essenciais ao seu trabalho. Já no século XIX, a ciência da história perdeu de vista a questão da importância na formação sociale ganhou ênfase na metodologia da pesquisa, separando-se das dimensões relacionadas à vida prática e concretizando a "cientifização" (RÜSEN, 2006, p. 9) da história, estreitando perspectivas, propósitos e finalidades da história. A esse caráter de cientificidade, o autor atribui a "irracionalização" da história, uma vez que percebe a mesma na sua indissociabilidade com a vida prática das sociedades. Para ele, a cientifização limitou e confinou os objetivos da história dentro das academias, considerando história somente o que é produzido no seu interior.

Essa situação pode, considerando especificidades, ser transportada para a realidade do ensino superior no Brasil e constatada em um número significativo de cursos de história de Instituições de Ensino Superior (IES) públicas, mas não só nos espaços públicos. Neles se percebe um vazio entre os cursos de formação e seus egressos, especialmente quando no já no exercício da profissão - a Universidade forma professores mas em raras situações demonstra ter uma política que expresse interesse em manter laços com os mesmos no que diga respeito ao fazer para o qual foram formados. Sobre a problemática, ela já era identificada em dissertação de mestrado a 
mais de uma década, na qual a autora expõe o importante distanciamento para com os profissionais do ensino de História, atuantes nas escolas de 1o. e 2o. graus de Santa Maria, em relação aos seus cursos de graduação (MARIN, 1997).

A realidade não se alterou na ultima década. As atividades relacionadas com a vida prática dos formados continuam carecendo de interesse no interior das IES, predominando a concepção de que o trabalho na escola básica não se relaciona com a dimensão cientifica da ciência histórica que se limita à academia.

Rüsen (2006) chama a atenção para a necessidade de reversão desse quadro. Segundo ele isso já acontece na Alemanha, onde a didática da história - interpretada originalmente como uma aplicação externa da escrita profissional da história, vem ganhando espaço e status nos cursos superiores com o objetivo de melhorar a compreensão histórica nas suas formas acadêmicas.

Conforme Rüsen, a didática em sua origem servia para treinar professores, o que acontecia em dois níveis, um dos métodos de ensino e outro nos propósitos de ensinar e aprender história. De acordo com o autor, o segundo nível deveria preceder o primeiro de modo que a didática da educação em história fosse desenvolvida considerando o contexto político, social, cultural e institucional. O segundo nível seria o da metodologia de instrução em história, no qual se definiriam os meios e instrumentos para alcançar os objetivos pretendidos.

Considerando o exposto, acredita-se ser adequado ponderar que nas $\mathrm{Li}^{-}$ cenciaturas em História de IES brasileiras a Didática do Ensino de História é uma disciplina do currículo obrigatório pautada no preparo do professor para planejar e desenvolver o conhecimento aprendido na academia no espaço da escola básica, mais especificamente nos Anos Finais do nível do Ensino Fundamental (6 $6^{\circ}$ ao $9^{\circ}$. Anos) e no nível do Ensino Médio (de três anos). Nessa disciplina, o "treinamento" de professores, que Rüsen chama de "metodologia de instrução em história" (Idem, p. 9), costuma acontecer em dois níveis: o dos métodos de ensino e o das teorias da história e da educação. Vejamos como.

No nível das teorias da história e da educação, uma leitura inicial de projetos pedagógicos de cursos que fazem parte deste estudo permite, neste momento, permite deduzir que o "treinamento" dos professores se concentra nas condições e nos propósitos básicos do aprender as interpretações da história e aprender a ensinar História. Isso através do estudo de vertentes teóricas da História, das escolas teóricas da Educação, e do desenvolvimento da compreensão dessas como norteadoras da postura profissional docente. Ou seja, no nível das teorias da história e da educação, um dos princípios que tem fundamentado a formação de professores de História é a do conhecimento, escolha e articulação, na prática de ensino, de concepção teórico-histórica com concepção teórico-educativa.

No outro nível, o dos métodos de ensino, a formação está orientada por concepções pedagógicas e psicopedagógicas que fundamentam atividades práticas durante o estágio. O nível dos métodos de ensino é compreendido, no geral, como algo que se constrói na prática e que se aprimora no decorrer da vida profissional docente. 
A concepção predominante ainda é a de que seja na sala de aula, no planejamento e na sua execução que se situa exclusivamente a perspectiva de construção de metodologias do ensino, ou seja, a partir das vivências e práticas, o que reforça a idéia que não seja a academia o espaço de pensar as práticas.

Esta forma de compreender e desenvolver a formação de professores, seus limites e contradições, favorece interpretar a criação e o significado atribuído a espaços de formação como os Laboratórios de Ensino de História (LEH). Ambientes constituídos em algumas IES públicas brasileiras a partir da década de 1980,no contexto de transição das ditaduras militares para a democracia, os LEH serviram, e alguns ainda servem, aodiálogo entre docentes do ensino superior, do fundamental e médio e com acadêmicos em formação. Sua existência permitiu o contato entre experiências, metodologias, técnicas e recursos que contribuíram com a formação inicial e continuada de professores, na transposição dos conhecimentos acadêmicos à escola, na consolidação da relação entre teoria e práticas docentes.

Embora algumas experiências de LEH, a concepção de processo formativo em geralcontinua carecendo da preocupação específica em ensinar a aprender a ensinar os conteúdos acadêmicos que serão desenvolvidos no âmbito da escola básica. A ação educativa se reduz a aprender a fazer fazendo, sendo tomada como uma competência que pertence à natureza quem escolhe andar pelos caminhos da licenciatura.

Aqui é provável que se localize um ponto importante para a cisão entre os conhecimentos acadêmicos e a sua utilidade na vida prática, entre a academia e as instituições de educação básica, entre os cursos de licenciatura e seus egressos. A aplicação prática dos saberes aprendidos na academia não é compreendida como ciência, e por isso não é merecedora de estudos científicos. Neste sentido, reporta-se novamente a Rüsen (2006:8), quando esse critica a concepção tradicional da didática da história na Europa ocidental como "uma disciplina que faz a mediação entre a história como disciplina acadêmica e o aprendizado histórico e a educação escolar. Assim, ela não tem nada a ver com o trabalho dos historiadores em sua própria disciplina”.

O que significa que ao concluir o curso superior o professor passa a trilhar um caminho solitário. Como referido anteriormente, se torna órfão na sua profissão, e na disposição em progredir em estudos de pós-graduação que contemplem a pesquisa sobre o ensino o caminho "naturalmente" apontado será o dos programas em educação. Entende-se que isso é o que Rüsen (2006) denomina de "irracionalização" da história. Fruto da "cientifização" da história, essa "irracionalização" resulta na exclusão da competência da reflexão histórica racional das dimensões do pensamento histórico inseparavelmente combinado com a vida prática.

A tese principal neste trabalho de Rüsen é a reversão desse processo, de retomada da Didática da História como meio para "novamente facilitar e melhorar o entendimento histórico, mas agora dentro das suas formas acadêmicas novas e altamente racionalizadas" (Idem, p. 9). Segundo Rüsen isso ocorre na Alemanha a partir das décadas de 1960-70, através de uma "grande reorientação cultural" (Idem: 10), e no contexto dela a expansão do sistema universitário, favorecendo uma nova geração 
de historiadores que almejavam firmar-se e legitimar-se no campo da educação. Eles abriram o debate sobre "importantes questões referentes à tarefa básica da cognição histórica e da função política dos estudos históricos" (Idem, p. 10), situação que repercutiu nas salas de aula da educação escolar através da crise de legitimidade do ensino de história. Foram introduzidos novos conteúdos e novas formas de abordagem, e o que aconteceu pode ser visto como uma mudança de paradigma. A Didática da História teve sua concepção alterada e transformada, não se limitando mais a simples transposição de formas, conteúdos e valores acadêmicos para a sala de aula. A questão básica emergente era se o conhecimento histórico e a forma de pensar a história consideravam a relação da educação histórica com a realidade. Ao desafio sobre o papel legitimador da história no âmbito da escola e na vida real, os historiadores alemães responderam ampliando o campo da auto-reflexão e do auto-entendimento histórico, começando por respeitar as esquecidas dimensões práticas dos estudos históricos. A reação de historiadores europeus à persistência da pedagogização da didática da história foi a de pressionar pela "peculiaridade e originalidade do pensamento e da explicação histórica e procuraram diferenciá-lo de outras formas de pensamento nas outras ciências sociais" (2006, p. 12), trazendo a didática para o centro dos debates históricos, contribuindo para a transformação do seu significado, para a abertura de pensamento sobre a Didática da História como ciência social histórica. Segundo Rüsen (2006, p.12), a "didática da história juntou os assuntos orientados pela prática sobre ensino e aprendizagem em sala de aula com uma percepção teórica dos processos e funções da consciência histórica em geral".

Essas condições e perspectivas, segundo Rüsen, deram à didática da história um novo encaminhamento que a colocou para além dos problemas de ensino e aprendizagem na escola, expandindo-se para a análise das formas e funções do raciocínio e do conhecimento histórico na vida cotidiana, abrindo novos campos de trabalho para os historiadores, todavia o estudo da história nesse âmbito, na Alemanha e nos outros países já citados da Europa ocidental, ainda está numa caminhada inicial, com resultados imprecisos.

As referências de Rüsen sobre a situação da didática da história favorecem um vínculo com a realidade brasileira, o qual pode se situar no tempo histórico, político e educacional da década de 1980-1990, quando frente às mudanças trazidas pela transição para a democracia no âmbito da educação brasileira propagaram-se reformas legislativas e curriculares. $\mathrm{O}$ pensamento educacional brasileiro entrou em efervescência num novo contexto levou à elaboração da nova Constituição Federal, da nova Lei de Diretrizes e Bases (LDB n. 9394/96), dos Parâmetros Curriculares Nacionais (PCN), em 1997, e daí a uma enxurrada de reformulações curriculares, assim como da retomada das relações entre IES e a escola básica. Neste contexto, a proximidade entre docentes dos diferentes níveis educacionais foi fundamental para aproximar-se de inovadoras pesquisas no ensino de história e das novas produções bibliográficas, as quais contribuíram para oxigenar o pensamento educacional brasileiro em grande parte. A aproximação, as trocas, os cursos de formação continuada fomentaram a necessidade de criação de espaços para essas trocas. Muitos Laboratórios de Ensino de várias disciplinas tiveram suas origens neste contexto, no final da década de 1980 e no decorrer da de 1990. Em escolas de educação básica foram criados Laboratórios de Ensino de 
Artes, Química, Física, Biologia, História, e neles circulavam docentes e acadêmicos, estudando, debatendo, formulando e reformulando interpretações e práticas de ensino.

A investigação até o momento realizada com fontes de LEH que são parte desse estudo ${ }^{1}$ permite inferir que, na origem eles se relacionam com a efervescência política e educacional do período entre 1980 e 1990, com as demandas de formação continuada manifestadas pelos egressos de cursos de História de IES, públicas ou não, e com a necessidade de criar espaços para abrigar debates sobre o ensino de história. Todavia, não se pode afirmar, como Rusen o faz para o contexto europeu (2006), que teria sido a reação de historiadores que, frente à manutenção da didática da história no campo das pedagogias, pressionaram os debates e a criação dos Laboratórios de Ensino. No caso brasileiro, e no caso dos LEH em estudo, o resultado das entrevistas mostra que a aproximação não se dá pela busca de um status para a Didática da História enquanto transformação do seu significado como ciência social histórica, e sim pela necessidade urgente de repensar o ensino da história e o seu significado no contexto da escola e na vida dos alunos, mas ainda relacionada à ciência pedagógica, à didática geral da educação e à psicologia da educação.

Mesmo considerando tais limites, entende-se que na origem a criação de Laboratórios de Ensino de História foi fundamental para que docentes e acadêmicos do ensino superior e docentes da escola básica repensassem e debatessem questões sobre o significado de ensinar e de aprender história. Especialmente foi fundamental para colocar em pauta o debate sobre a difícil relação entre as teorias da história e a prática docente, entre o conhecimento cientifico aprendido na academia e o processo de ensino e aprendizagem na escola. Neste sentido, acredita-se poder afirmar que os Laboratórios contribuíram para fomentar elementos de ruptura com um ensino de história tradicional essencialmente factual, linearmente cronológico e de apologia aos personagens heróicos, situação bastante comum no contexto brasileiro. Os debates sobre ensino de história nos LHE até o momento investigados, no período delimitado nesse projeto, mesmo que na maioria pautados na didática geral e em concepções pedagogizantes, contribuiu para novos debates e enfoques que trouxeram à tona o estudo de novos espaços considerando outros atores, que no conjunto da sociedade passam a ser considerados como promotores das mudanças sociais.

Sobre o novo encaminhamento da Didática da História no seu país e em outros da Europa ocidental, Rüsen chama a atenção para recursos humanos, cuja formação ele considera insuficiente. Para ele ainda é uma questão aberta se a didática da história terá um eco positivo. "O que deveria ser evidente é que as habilidades normais adquiridas pelo historiador profissional não são suficientes para a execução dessa mediação" (2006, p. 12-13).

Essas colocações alertam para a realidade da formação inicial e continuada de professores no Brasil. A crise pela qual passam as licenciaturas, e que se acentuou na segunda metade dos anos de 1990, manifesta-se na progressiva queda da procura de vagas nos cursos superiores, nas políticas públicas que minimizam a importância do professor através de vários instrumentos, entre eles baixos salários, excesso de alunos, turmas e carga horária. Esses fatores comumente são os que mais chamam a atenção, 
todavia há que considerar que o trabalho dos profissionais da educação tem demonstrado limites. Embora não seja considerado o melhor meio para medir a qualidade em educação, as avaliações realizadas através do Sistema Nacional de Avaliação da Educação Superior (Sinaes), do Exame Nacional de Desempenho dos Estudantes (Enade) e do Sistema de Avaliação da Educação Básica (SAEB), contribuem para percepção relativa dos níveis educacionais, marcada pelos baixos índices de aproveitamento e crescente evasão. A divulgação desses resultados, independente do mérito, contribui para colocar em cheque o trabalho docente e a sua formação e fomentar o debate.

Assim, refletindo sobre o contexto brasileiro relativo à ampliação do "campo da auto-reflexão e do auto-entendimento histórico", e ao "respeitar as antes esquecidas dimensões práticas dos estudos históricos”, referidas por Rüsen (2006, p. 11) ao exercício realizado pelos historiadores alemães, entende-se necessário que historiadores brasileiros acrescentem ao debate que já ocorre desde a segunda metade da década de 1980, a reflexão sobre concepções e práticas no respeito do processo formativo. O que significa romper com o romantismo que cerca a ideia de formação de pesquisadores para a ciência histórica essencialmente, sem a conexão com a formação de professores pesquisadores.

Interessa abordar também, na análise de Rüsen, tópicos atualmente debatidos a respeito daDidática da História na Alemanha, os quais ele relaciona como: metodologia de instrução; funções e os usos da história na vida pública; estabelecimento de metas para a educação histórica nas escolas e a verificação se estas têm sido atingidas; e análise geral da natureza, função e importância da consciência histórica (Idem, p. 13). Sobre eles, dar-se-á mais ênfase aos que convergem com os interesses datese que origina esse artigo.

Considerando a metodologia da instrução, Rüsen afirma que o ensino nas escolas alemãs tem sido uma atividade mecânica, centrada no currículo. "Ainda não se resolveu como a peculiaridade da consciência histórica - aquelas estruturas mentais e processos que constituem uma forma específica de atividade cultural humana - pode ser integrada nesse padrão de educação" (Idem, p. 13). Ele afirma que isso ocorre porque há um distanciamento entre o planejamento do professor e o treinamento que ele recebe em sua formação, parecendo referir-se ao distanciamento entre a academia e a escola básica, entre o ideal e o real. Também afirma que as discussões sobre consciência história e fatores constitutivos do pensamento histórico se mantém afastadas das salas de aula e do processo de ensino e aprendizagem que nelas ocorre. Ele exemplifica do seguinte modo: no nível abstrato sabe-se como a história se constrói, mas não como ela é percebida e os efeitos que o seu aprendizado provoca no mundo prático; não se sabe como a história é apreendida no processo de ensino e aprendizagem, ou seja, como os alunos aprendem história nem como fazem uso do que aprendem.

Essa situação remete seguramente à dicotomia entre teoria e prática. No Brasil essa situação pode ser percebida na insegurança demonstrada pelos professores a respeito dos resultados do seu trabalho com os alunos. Como essa questão pode ser percebida no cotidiano escolar? Algumas considerações talvez coloquem luz sobre a questão, como por exemplo: no planejamento por objetivos ou por competências - os 
mais comuns usados na escola brasileira na atualidade, o professor nem sempre volta a revê-lo e verificar se e quais lograram ser alcançados. Isso ocorre, muito provavelmente, devido às lacunas no processo formativo, no qual costuma ser minimizada a importância da formação para o ensino, às condições de trabalho na escola - pouca carga horária para o desenvolvimento dos conteúdos, excesso de alunos e de turmas, divisão de regime de trabalho em duas ou mais escolas. Esses são alguns fatores que dificultam a muitos professores de, minimamente, conhecerem seus alunos e consequentementede desenvolverem um processo avaliativo sobre a execução do seu planejamento. Sendo assim, é possível concluir que as atividades de ensino nas escolas brasileiras, a exemplo do que coloca Rüsen (2006) sobre as escolas alemãs, também estão centradas no mecanicismo, restritas ao desenvolvimento de conteúdos curriculares através de metodologias e recursos respaldados por uma didática generalizante.

Sobre a análise das funções e usos da história na vida pública, ou seja, sobre a função do conhecimento e da explicação histórica na vida cotidiana, Rüsen afirma que há pouca produção ainda que permita elucidar esse tópico nas discussões sobre didática da história. Ainda se dão os primeiros passos na definição da disciplina, quais seus problemas, o que pode e o que deve ser feito. Para isso ele aponta o diálogo com outras áreas e que passaria pela aproximação, na escrita da história, com outras formas, como a de comunicação de massa usada por este meio de comunicação. Todavia, se bem se compreendeu essa proposição do historiador, entende-se como fundamental que o campo da escrita da história seja o campo dos especialistas em história ${ }^{2}$. No Brasil, o diálogo que vem se estabelecendo ainda timidamente com outros campos das ciências sociais e compreende áreas como sociologia, antropologia, paleontologia, psicologia.

Sobre estabelecer os objetivos da educação histórica e descobrir como estes objetivos têm sido alcançados, sobre o estabelecimento de metas para a educação histórica nas escolas e a verificação se estas têm sido atingidas, segundo Rüsen, "Posto que esta discussão ainda esteja por ser resolvida, [...]. História como uma matéria a ser ensinada e aprendida tem de passar por um exame didático referente à sua aplicabilidade de orientar para vida" (Idem, p. 14).

$\mathrm{Na}$ análise da natureza, função e importância da consciência histórica, esta última Rüsen a define como uma categoria, a qual apenas tem relação com o aprendizado e o ensino de história e sua análise atende aos estudos históricos e à função da história na vida pública e privada. Aprofundando a análise Rüsen menciona três pontos que considera relevante.

Primeiro, a consciência histórica não pode ser meramente equacionada como simples conhecimento do passado, ou seja, disponibilizada como um conjunto de dados para conhecer o passado, uma vez que ela "dá estrutura ao conhecimento histórico como um meio de entender o tempo presente e antecipar o futuro". (Idem: 14) Ela combina de forma complexa a compreensão do passado a partir da necessidade de entender o presente e pressupor o futuro. A percepção, por parte dos historiadores, da conexão entre as três dimensões do tempo na estrutura da consciência histórica, poderia superar a ideia equivocada de que a história trata somente do passado, não tem nada a fazer com os problemas do presente e muito menos com os do futuro. 
Segundo, a "consciência histórica pode seranalisada como um conjunto coerente de operaçõesmentais que definem a peculiaridade dopensamento histórico e a função que ele exercena cultura humana" (Idem, p. 14), sendo que essas operações mentais se manifestam na narrativa histórica. Para abordar sobre a estrutura narrativa da explicação histórica, Rüsen usa pensadores contemporâneos como Hayden White e Paul Ricoeur, os quais vêem a narração histórica como um "procedimento mental básico que dá sentido ao passado com a finalidade de orientar a vida prática através do tempo" (Idem, p. 15). A defesa de Rüsen, apoiado nos pensadores citados, caminha no sentido de que as peculiaridades da narrativa histórica aproximem o conceito da disciplina de história do que era recorrente no passado, o qual seja o de cumprir um papel central no processo de reflexão na atividade dos historiadores, e superando sua cisão com as necessidades da vida prática. É possível que a superação desta cisão contribua para que a escrita da história passe a contemplar elementos que fundamentem estruturas de pensamento que subsidiem a consciência história no sentido de dar significado e orientação à vida presente e perspectivas futuras, a partir do conhecimento histórico do passado.

Terceiro, "pela orientação da vida atravésda estrutura do tempo, a didática da históriapode trazer novos insights para o papel do conhecimentohistórico e seu crescimento na vida prática" (Idem, p. 15), ou seja, Rüsen compreende como possível aprender, considerando a estrutura temporal passado, presente e futuro, que a consciência histórica possa exercer um papel importantenas elaborações de pensamento que organizam a identidade dos seres humanos, capacitando-os para a autopreservação através da interação social. Nessa questão de identidade histórica, a didática da história e a educação histórica são um "processo intencional e organizado de formação de identidade que rememora o passado para poder entender o presente e antecipar o futuro, então [...] não pode ser posta de lado como sendo alheia ao que diz respeito aos historiadores profissionais (RÜSEN, 2006, p. 15).

Considerando esse argumento pondera que historiadores profissionais, no processo de pesquisa e escrita da história, não teriam mais porque ignorar que o ensino e aprendizagem da história fazem parte da construção das identidades dos sujeitos envolvidos no processo educativo. Seriam então as operações envolvidas na construção daconsciência histórica, respaldadas no uso da razão, que asseguram que os seres humanos, frente às mudanças, persistam nas suas metas. E conclui que "Esta razão pode ser aplicada a todas as formase usos do pensamento histórico onde argumentos,e não poder e dominação poderiam resolverproblemas" (Idem, p. 15).

A contribuição do autor ao papel do conhecimento e sua relação com a vida prática vem se coadunar com as reflexões que fazem parte dos debates educativos de um modo em geral, no Brasil, e especificamente sobre o papel do conhecimento histórico e seu significado na vida prática - respaldados que estão por instrumentos legais como, de um modo geral a LDB no. 9394/96 e, especificamente, nos Parâmetros Curriculares Nacionais (PCN) da História para a Educação Básica.

Todavia, mesmo considerando os aportes legais e variáveis sugeridas através dos PCN e os debates e reflexões que acompanham os processos formativos, as 
ações que poderiam contemplar a relação do conhecimento com a vida prática, na escola, ainda carecem de muita reflexão, debates e especialmente iniciativas pautadas na consciência do que seja realmente essa relação e na clareza do seu real significado na vida dos alunos.

Para melhor compreensão sobre a questão, Rüsen $(2007 b)^{3}$ se propõe a abordar qual o sentido prático do saber elaborado pela pesquisa e pela produção historiográfica no processo de conhecimento da ciência da história. Ou seja, no aprendizado da história, qual a contribuição da pesquisa e da historiografia para a aplicação prática desse conhecimento. Como se efetiva o que Rüsen conceitua como práxis, pois o efeito sobre a vida prática é fundamental no processo de conhecimento histórico, e por isso deve estar integrado às concepções e formas de desenvolver os conteúdos históricos.

Rusen (2006), idem (2007b) afirma que os historiadores, em relação à produção, têm sempre a intenção de produzir algum efeito sobre a vida prática. Todavia, em relação a isso, nunca o fazem com suficiente clareza. Como a neutralidade não existe, os historiadores têm seu trabalho invariavelmente permeado por intenções relacionadas à vida prática. Ele acredita que essas relações devam ser administradas com consciência, longe do falso muro da neutralidade, o que não significa, em hipótese alguma, "escancarar as portas da argumentação especializada a fins políticos". (2007b: 86). A ciência histórica deve poder preserva-se, sustentando-se sob a autoridade que lhe vem do próprio conhecimento da história, conhecimento que é fundamental para subsidiar decisões políticas na vida prática com seriedade e responsabilidade.

Voltando à relação específica do saber histórico com a vida prática, trata do conceito de práxis, o qual entendecomo "[...] função específica e exclusiva do saber histórico na vida humana. Isso se dá quando em sua vida em sociedade, os sujeitos têm de se orientar historicamente e tem que formar sua identidade para viver - melhor: para poder agir intencionalmente" (Idem, 2007b, p. 87).

Desta forma, o entendimento de práxis a partir de Rüsen compreende um tipo de relação do saber histórico com a vida prática que capacite aos sujeitos ${ }^{4}$, não só para se orientar nessa realidade, sabendo como atuar na mesma e com a mesma, mas para que esta atuação esteja apoiada no autoconhecimento, ou seja, na clareza da própria identidade do sujeito.

Este "orientar historicamente" significa um duplo movimento: para dentro, que diz respeito à identidade; e, para fora, em relação à práxis, sendo este duplo movimento o objetivo, a lógica e a dinâmica de qualquer pensamento histórico. Entende-se aí a responsabilidade dos historiadores no seu trabalho, e a própria crise que acompanha o ensino de história, expressa em questões manifestadas pelos alunos: Para que estudo história? Que destino dou ao que aprendi em história? Por que tenho que aprender este ou aquele conteúdo?

Sobre isso Rüsen (2007b) dispõe a importância e a questão central da didática, como componente curricular de caráter científico ao qual cabe realizar essa intenção de ligação entre pensamento histórico e vida prática, realização essa que acontece no percurso do processo de aprendizagem. Aqui se faz necessário buscar a definição 
rüseniana de didática. Segundo ao autor, apoiado em Blanke e Pandel, a didática tradicionalmente compreendia "ensinar e aprender a história, de saber como escrevê-la a fim de que seus destinatários aprendessem alguma coisa para a vida." (Idem: 88). Assim, ensinar, aprender e escrever história estava, até final do século das Luzes, relacionado à didática. A forma, o método, a totalidade de como ocorria a relação entre o conhecimento histórico e seu significado prático eram atribuições do terreno da didática, fundamentada como ciência teórica e metodológica.

$\mathrm{Na}$ atualidade, Rüsen descreve que na concepção de didática, "Os didáticos seriam transportadores, tradutores, encarregados de fornecer ao cliente ou à cliente comumente chamado de "aluno" ou "aluna" - os produtos científicos" (2007b:89).

À didática também é atribuída “[...] o assim chamado aspecto de 'mediação' [...] assumir, inalterados, os conteúdos e forma produzidos pela história como ciência. A única adaptação aceita é a que depende da capacidade de absorção gradual ou reduzida dos destinatários [...]" (Idem, p. 89).

Esta dura, porém real, interpretação que Rüsen faz sobre o papel da didática hoje reproduz a condição majoritária dessa representação da didática entre aqueles historiadores que se auto-atribuem o direito e a autoridade exclusiva de escreventes da história. Presume-se, por aí, que o que seja contexto muito próprio das instituições educativas no Brasil tenha suas raízes no velho continente europeu. É merecedor de reflexão que as origens desse tipo de pensamento na universidade e na escola brasileira tenham cruzado os mares, vindas do leste, e aqui encontrando amplo campo para expansão.

No que concerne a entender como ocorre a relação teoria e prática na formação de professores de história acredita-se ser de fundamental importância o aprofundamento, na continuidade do presente trabalho, da compreensão do conceito de didática da história e de sua função na construção do conhecimento histórico e da relação deste ultimo com a vida prática. Isso é essencial para subsidiar os elementos de permitirão apresentarem discussão sobre quais seriam os fundamentos de uma concepção de Laboratório de Ensino de História a partir da didática da história fundamentada na Educação Histórica. Entende-se ser este o caminho que possibilitará compreender os LEH como espaços de reflexão, debates e ações que viabilizem o processo da Educação Histórica a partir da relação entre o conhecimento histórico e a aplicabilidade prática deste, entre a formação do especialista nos conhecimentos da história e especialista em ensinar a história, esta totalidade compreendida em um mesmo profissional.

Neste sentido, Rüsen (2007b) aponta para o mutuo envolvimento entre teoria da história e didática da história, considerando que "aprender é um ato elementar da vida prática, do qual decorre o conhecimento histórico e no qual este desempenha (ou pode desempenhar) seu papel próprio, correspondente à cientificidade." (Idem, p. 92). Ou seja, um não pode dispensar o outro. Rüsen destaca que em geral, nos cursos de história, o trabalho com a didática da história começa pelo estudo das teorias da história, e isso faz com que "a dimensão originária fundamental, na qual se realiza o 
aprendizado histórico, é deixada de lado depressa demais"(Idem, p. 92). Considerando essa observação, rememora-se que essa prática é existente em cursos de história de universidades brasileiras. A abordagem começa pelo conhecimento e estudo das teorias da história (no qual é investida a maior parte da carga horária da disciplina), seguida depois pelo conhecimento e estudo das teorias da educação. Então, na já minguada carga horária restante, acontece a abordagem de metodologias, técnicas e recursos que poderão ser usados em sala de aula nas práticas de ensino. É importante observar que há, entre os acadêmicos - depois professores, clareza sobre as concepções que norteiam as teorias da história, mas sobre a relação destas com o processo de ensino paira uma nuvem de imprecisões. Essa nuvem acompanhará o professor, geralmente, pela maior parte de sua vida profissional, daí a ânsia de muitos por formação continuada.

Segundo Rüsen, a didática não pode se respaldar unicamente nas teorias da história, pois como ciência seu fundamento existencial vem de questões e problemas práticos da vida cotidiana. Neste caso, ele considera importante superar interpretações unilaterais, as quais podem ser superadas se "ficar claro que a teoria da história e a didática possuem o mesmo ponto de partida, mas se desenvolvem em direções cognitivas [...] e com interesses cognitivos diversos. [...] A teoria da história pergunta pelas chances racionais do conhecimento histórico e a didática pelas chances de aprendizado da consciência histórica" (2007b, p. 93).

No presente artigo conclui-se, parcialmente, que a relação entre teoria da história e didática da história, deva ser mútua, "de imbricação recíproca" (idem: 92), na qual a teoria da história cuida de questões didáticas na medida em que dizem respeito ao processo científico do conhecimento na produção, no ensino e no aprendizado da história. Compreende-se que é importante superar as ideias relacionadas a hierarquias, subordinações ou ameaças de prejuízo no desempenho, considerando sim o estatuto próprio de cada uma delas, mas levando em conta a sua totalidade como elemento fundamental no processo de formação de professores e no ensino da história.

\section{Referências}

BRASIL. Lei de Diretrizes e Bases da Educação Nacional, LDB 9.394, de 20 de dezembro de 1996. Estabelece as diretrizes e bases da educação nacional. Disponível em: www.senado.gov. br/legislação/.

MARIN. M. F. A transição democrática e os obstáculos ao desenvolvimento de uma proposta de ensino da história no cotidiano escolar de Santa Maria/RS. Dissertação de Mestrado, Santa Maria, 1997.

RÜSEN, J. Didática da História: passado, presente e perspectivas a partir do caso alemão. Tradução de Marcos Roberto Kusnick. In: Práxis Educativa. Ponta Grossa, PR., n. 2, p. 07-16, jul. - dez. 2006, V.1.

. História viva. Teoria da história III: formas e funções do conhecimento histórico. Tradução de Estevão de Rezende Martins. Brasília: Editora Unniversidade de Brasília, 2007b. 


\section{Notas}

${ }^{1}$ Laboratório de Ensino de História/Universidade Estadual de Londrina/Londrina/Paraná; Laboratório de Ensino de História/Universidade Federal de Santa Maria/Santa Maria/Rio Grande do Sul; Laboratório de Ensino de História/Universidade Federal de Uberlândia/Uberlândia/Minas Gerais, todos no Brasil.

${ }^{2}$ Sem negar a importância do diálogo com outras áreas, refiro-me a profissionais da área do jornalismoque vem produzindo a escrita da História, no Brasil, sem definir claramente critérios de investigação, parecendo mais atender a um certo veio especulativo do mercado editorial.

${ }^{3}$ A compreensão de sujeito de Rüsen se aproxima significativamente do conceito de sujeito de Paulo Freire. Para mais consultar FREIRE, Paulo. Pedagogia do Oprimido, cap 3.

* Professora doutora da Universidade Federal de Santa Maria, Silveira Martins, Rio Grande do Sul, Brasil.

\section{Correspondência}

Jorge Luiz da Cunha - Universidade Federal de Santa Maria, Unidade Descentralizada de Educação Superior da UFSM em Silveira Martins. Rua Francisco Guerino, 407, Centro, CEP: 97195000, Silveira Martins, Rio Grande do Sul - Brasil.

E-mail:jlcunha11@yahoo.com.br

Recebido em 21 de julho de 2015

Aprovado em 06 de agosto de 2015 